\title{
The effect of multiple usages of nickel-titanium rotary endodontic files on cutting efficiency
}

Albert L. Tomsic Jr.

West Virginia University

Follow this and additional works at: https://researchrepository.wvu.edu/etd

\section{Recommended Citation}

Tomsic, Albert L. Jr., "The effect of multiple usages of nickel-titanium rotary endodontic files on cutting efficiency" (2009). Graduate Theses, Dissertations, and Problem Reports. 2787.

https://researchrepository.wvu.edu/etd/2787

This Thesis is protected by copyright and/or related rights. It has been brought to you by the The Research Repository @ WVU with permission from the rights-holder(s). You are free to use this Thesis in any way that is permitted by the copyright and related rights legislation that applies to your use. For other uses you must obtain permission from the rights-holder(s) directly, unless additional rights are indicated by a Creative Commons license in the record and/ or on the work itself. This Thesis has been accepted for inclusion in WVU Graduate Theses, Dissertations, and Problem Reports collection by an authorized administrator of The Research Repository @ WVU. For more information, please contact researchrepository@mail.wvu.edu. 


\title{
The Effect Of Multiple Usages Of Nickel-Titanium Rotary Endodontic Files On Cutting Efficiency
}

\author{
Albert L. Tomsic Jr. \\ Thesis submitted to the \\ School of Dentistry \\ at West Virginia University \\ in partial fulfillment of the requirements \\ for the degree of \\ Master of Science \\ in \\ Endodontics
Michael Bagby, DDS, PhD, Chair
Russell Jackson, DDS, MS
Mohssen Ghalichebaf, DDS, MS \\ Department of Endodontics \\ Morgantown, West Virginia \\ 2009
}

Keywords: Nickel-Titanium rotary files, endodontic, cutting efficiency, multiple usages 


\title{
ABSTRACT \\ The Effect Of Multiple Usages Of Nickel-Titanium Rotary Endodontic Files On Cutting Efficiency
}

\author{
Albert L. Tomsic Jr.
}

Nickel-titanium rotary (NTR) files have been used in endodontic therapy to efficiently clean and shape root canals since the early 1990's. These files are the single most expensive disposable clinical supply used in non-surgical endodontics. When NTR files are new, they are being used in their sharpest state, with the least probability of breaking and their highest cutting efficiency (CE). As they are used in successive cases in order to contain clinical expenses, an increased risk of file separation occurs, possibly along with a decreased $\mathrm{CE}$.

The purpose of this study was to determine the measurable changes in CE of NTR files as they are used in five simulated clinical situations. Three brands of NTR files were chosen for their distinct design features. The Brasseler EndoSequence is a nonlanded, negative rake angle file. The Sybron Endo K3 is a non-landed, positive rake angle file. And the Dentsply ProFile is a landed, negative rake angle file. Ten files of each brand were tested, one of which was used as the negative control. Clinical use was simulated by instrumenting two canals of extracted human teeth. CE was determined using acrylic endodontic training blocks, measuring depth of penetration of the file and the mass change of the block from the material removed.

The results of this study support that the relative degree of $\mathrm{CE}$ between brands of NTR files could be predicted by their cross-sectional design. The Brasseler file (negative rake angle, non-landed) had an overall greater $\mathrm{CE}$ than either the $\mathrm{K} 3$ (positive rake angle, landed) or ProFile (negative rake angle, landed).

Also supported is the notion that the sharper the file's cutting edges, the quicker it will dull. This was evident by the CE change between Trials 1 and 2 of the Brasseler file. But once this change in CE had occurred, the CE for the Brasseler and the other two file brands did not change significantly over the five clinical trials.

Therefore, multiple usages of these NTR files did not show a significant decrease in CE over the course of five simulated clinical trials. 


\section{Dedication}

For Andrea': Thanks for tolerating me and my big ideas. As for life-changing things that I want to try, this oughta do it.

Now, let's go and get some land...

No, wait! I want to be an artist! 


\section{Acknowledgements}

Dr. C. Russell Jackson: Thank you for the opportunity, the guidance, that broad, massive knowledge base of yours (your Theoda Light is aglow with a swanky surveillance of swoopiness), your library of witty and always appropriate aphorisms ("As useless as a whistle on a kraut cutter") and for letting me be me. Everything I know about Balanced Force, I learned from you (and from those articles you "suggested" I read). And I learned a lot about handling people.

Dr. Michael Bagby: Irreplaceable, irrepressible and, some say, irresponsible with a red pen. Thanks for guiding my project (your ninth job at the SOD).

Dr. Mohssen Ghalichebaf: Thank you, Dr. Mo, for being on my committee, your contribution to this project and for being one of my first friends when I was new here.

Dr. Bryant Stowe: I enjoyed our two years and learned a lot from you ("The Prions of Kakehashi" being one of my favorite papers).

Dr. Spencer Stiles: Although you barely got into the program, you've made the most of it. You taught me a lot about being nice. Without you, I would never be roundly recognized as one of the nicest people in the school.

Dr. Gavin Criser: May you achieve your goals of becoming an endodontist, driving an $\mathrm{H} 7$, having your own universe, and getting away with murder.

Dr. Mark Richey: Your legacy lives on in the endo residents' room. One of the most genuine people I have ever met. The end.

Dr. Kent McBride: Thanks for your kindness and hospitality when I would stop to visit before getting in the program.

Melody Gwilliam: Thanks for your dedication in keeping the department running smoothly, getting my name on the corner of that birthday cake, and making me feel good by at least trying to laugh at my jokes. Best of luck on your journey! 
Cathy Myers and Gina White, our esteemed assistants: You two are just peas in a pod. Okay, maybe I'd better separate this...

Cathy Myers: Thanks, Cathy. Many good conversations while packing gutta percha. May you (and Dixie) have many years of health, happiness and good books.

Gina White: Gina, thanks for your dedication. I know that you would get out everything, every time, if you were asked.

To all of the really outstanding dental students: Thank you for showing up in clinic eager, prepared to work and quietly aware that you would accomplish something from which you would learn.

For all of those who tolerated my impromptu visits into your offices or cubicles, or just stopping you at the end of the hallway to discuss "deep things": That includes you, Julie Wolford, Dr. Erica Reed, Dr. Chris Martin and Dr. Mike Meador.

Don at Cavanaugh's: Thanks for all of the free coffee.

Last but certainly not least, Elizabeth Tomsic: Thanks, Mom. You are a rock. I know that you'd support me even if I announced that I wanted to sell umbrellas on a beach. 


\section{TABLE OF CONTENTS}

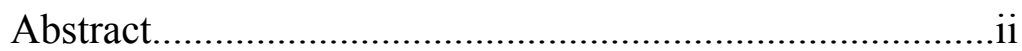

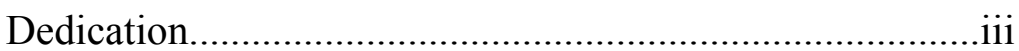

Acknowledgements.............................................................

Table of Contents.................................................................

List of Tables.............................................................................

List of Graphs.................................................................... vii

List of Figures.............................................................................

Chapter 1 Introduction.........................................................

Chapter 2 Review of Literature...........................................

Chapter 3 Materials \& Methods............................................19

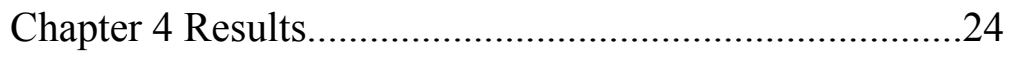

Chapter 5 Discussion...........................................................

Chapter 6 Conclusions............................................................39

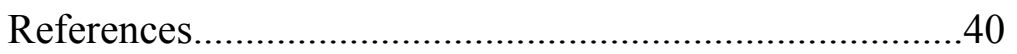

Curriculum Vitae.................................................................4 


\section{List of Tables}

Table 1: Penetration(mm) by File Brand ............................................25

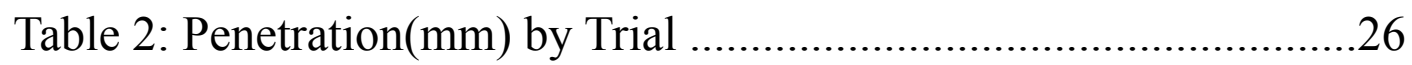

Table 3: Means for D-Mass(mg) by File Brand ..................................27

Table 4: Means for D-Mass(mg) Arranged by Trial.............................28

Table 5: D-Mass(mg) Arranged by Means ........................................29

Table 6: D-Mass(mg) Means by File, Trials \#2 - 6 ............................30

\section{List of Graphs}

Graph 1: Mean Penetration(mm) by File Brand ................................25

Graph 2: Mean Penetration(mm) by Trial. ........................................26

Graph 3: Means for D-Mass(g) by File Brand ...................................27

Graph 4: Least Square Means for D-Mass.......................................29

Graph 5: D-Mass(g) Least Square Means by Trial and File Brand.......31 


\section{List if Figures}

Figure 1: Definition of terms …………………………................

Figures 2 \& 3: Brasseler EndoSequence File......................................6,34

Figure 4: Sybron K3 NTR File ………………………………..........

Figure 5: Dentsply - Tulsa ProFile.......................................................36 


\section{Chapter 1: Introduction}

Nickel-titanium rotary (NTR) files have been used in endodontic therapy in various forms to efficiently clean and shape root canals since the early 1990's(34). The manufacturers recommend that these instruments be limited to use on a single endodontic case and then discarded. These files are the single-most expensive disposable clinical supply used in nonsurgical endodontics. When NTR files are new, they are being used in their sharpest state, with minimum probability of breaking and maximum cutting efficiency (CE). Some practitioners ignore the single-use recommendation in an effort to keep overhead costs down and use the NTR files multiple times.

In an effort to determine the loss of CE with multiple uses of the NTR files, this study intends to measure the $\mathrm{CE}$ of the files when new and after five usage cycles. Each usage cycle of a file entailed instrumentation of two canals of extracted human teeth, heat sterilization, and the CE again determined. The cycle of instrumenting, sterilization and measurement is repeated four more times. Therefore, there will be six CE's recorded for each file. Ten files of each brand were tested, the tenth file used as a control (no human teeth were instrumented by the control, nor was the control file sterilized). Three brands of NTR files were tested, all .06 taper, ISO size \#35. A CE measurement is based on the penetration of a rotating file into an acrylic endodontic 
training block of a hardness comparable to dentin(31,32). CE was measured by the maximum penetration depth of the rotating file $(250 \mathrm{rpm})$ with constant, controlled force $(2.0 \mathrm{~N})(33)$ into an acrylic endodontic training block with a lumen of $0.20 \mathrm{~mm}$ diameter. Mean values of CE for each specific cycle (first through sixth for each file type) was calculated and statistically evaluated.

\section{Statement of the Problem}

What is the effect of multiples uses of NTR files on their CE?

\section{Significance of the Problem}

Single use of the NTR files means better cutting efficiency and less chance of separation, but at a higher cost per procedure. With multiple uses, CE would be expected to decrease, the probability of breakage would be expected to increase, but at a lower cost per procedure. Knowledge of the efficiency of the NTR files after a set number of uses and corresponding sterilization cycles is clinically practical. A decrease in CE could mean an increase in treatment time, possibly negating the benefits of using the NTR files for multiple cases. 


\section{Hypothesis}

There is no statistically significant difference in cutting efficiency of NTR files when new and files which are used and sterilized multiple times. 


\section{Definition of Terms}

Cutting efficiency - the ability of an endodontic instrument to remove material, measured as maximum penetration depth of the instrument into the lumen of an acrylic endodontic training block or the mass of material removed.

Cleaning ability - the ability of the instrument to remove the debris.

Taper of the file - the amount a file diameter increases each millimeter along its working surface from the tip toward the file handle.

Flute - the groove in the working surface of the file used to collect soft tissue and dentin chips removed from the wall of the canal.

Chip space - the space between the canal walls and the instrument that allows for the removal of debris as the instrument cuts.

$\underline{\text { Lands }}$ - the surface that projects axially from the central axis as far as the cutting edge between flutes.

Cutting edge - the surface with the greatest diameter that follows the groove (where the flute and land intersect).

Rake angle - the angle formed by the leading edge (cutting edge) and radius if a file would be sectioned perpendicular to its long axis. 
Positive rake angle - cuts (active cutting blade).

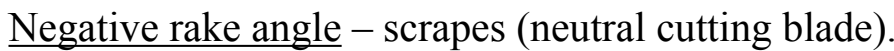

Helix angle - the angle the cutting edge forms with the long axis of the file.

Alternating Contact Point - the cutting edge design of the Brasseler

EndoSequence file which varies the radius of the cutting edges so that not all cutting edges are in contact with the canal wall at the same time.

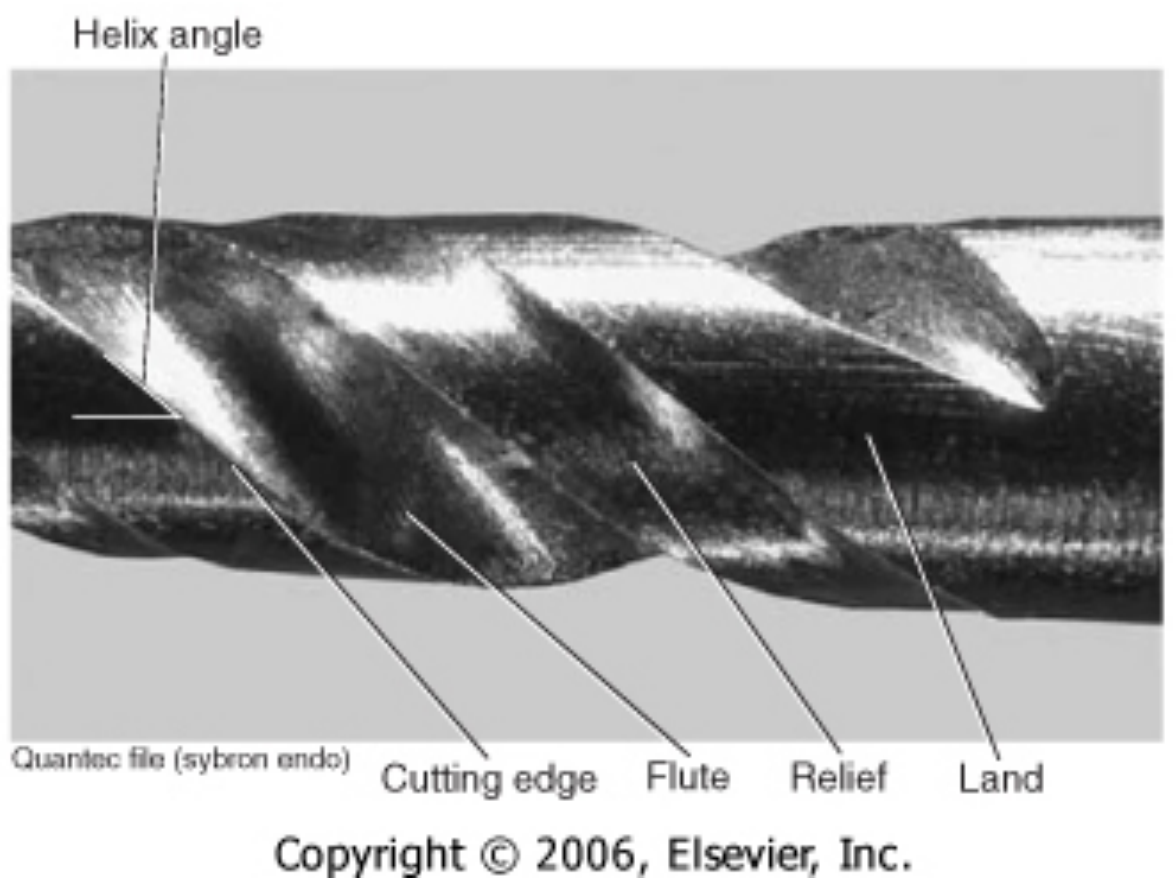

Figure 1: Definition of terms 


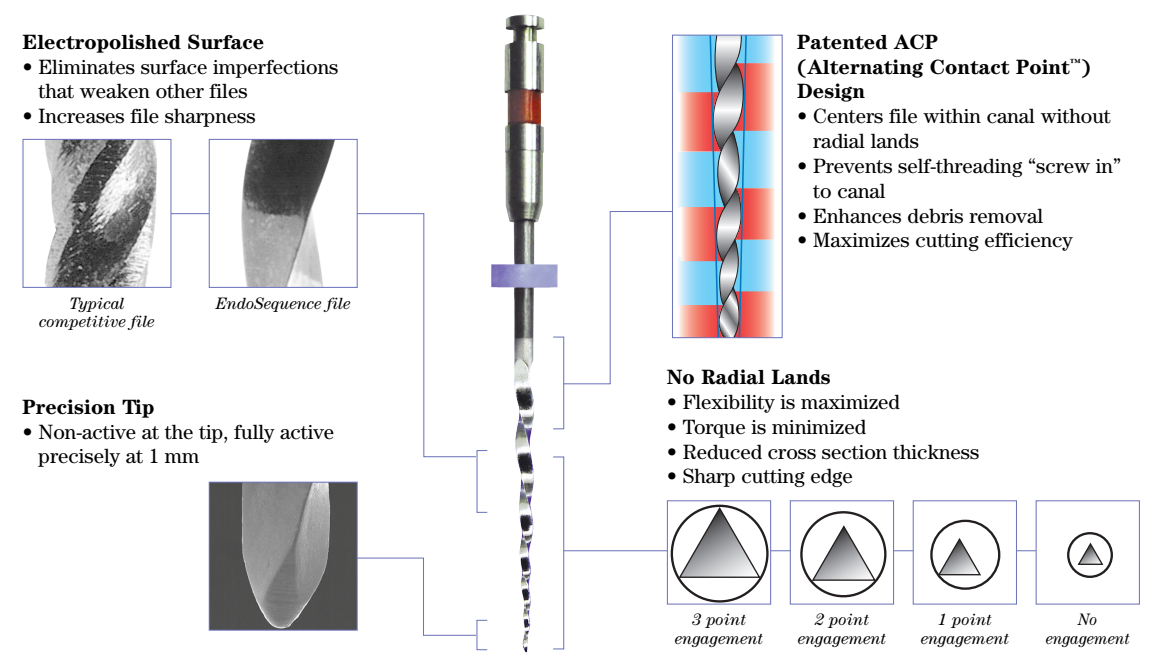

Figure 2: Brasseler EndoSequence File

\section{Assumptions}

The acrylic blocks to be used will be of a hardness that simulates the hardness of dentin.

In addition, the lumen of each block will be within a specific tolerance so that variations in lumen size will not adversely affect the data collected. Each of the brands of the NTR files purchased for testing will be of a standard quality for that file. The amount of force and rate of movement used to guide each file into the lumen of the acrylic block will be similar for 
each trial. The process of instrumenting two canals per trial of each file will sufficiently simulate the clinical usage of one appointment.

\section{Limitations}

In order to simulate clinical wear, the files will be used to instrument two canals of human teeth in a way that should simulate clinical use. This is an arbitrary and uncontrolled method, not unlike actual clinical usage. A single clinical use could include anywhere from a single canal to a multiple canalled tooth ( 4 or more canals) with varying degrees of tightness, hardness and curvature. Using each file in two canals seemed to be a reasonable average. Also, no human tooth was eliminated from use due to canal type, again to simulate practical clinical conditions.

\section{Delimitations}

Only three brands of files will be tested. All files will be $.06 / \# 35$ (.06 taper/ size \#35 - 0.35 $\mathrm{mm}$ at Do). The acrylic blocks will have a lumen of $0.20 \mathrm{~mm}$.

Clinical experiences would vary with regards to tightness and/or curvature of canals. This study will be limited to lumen of $0.20 \mathrm{~mm}$ in width with no curve. 


\section{Chapter 2: Review of Literature}

Since their advent, NTR files have been shown to have many advantages over hand files. These include better cleaning and shaping abilities with less canal transportation, faster instrumentation and better maintenance of the working length(18).

Schafer(18) showed in 2001 the Hero 642 NTR files demonstrated these qualities better than with a reaming motion with stainless steel K-Flexofiles. This study was conducted using simulated canals made in clear polyester resin blocks. These resin blocks were chosen for the precision of canal size, curvature and taper to measure the cutting efficiency (CE) of instruments.

Canals in real teeth can vary greatly. The resin is cut more quickly and therefore changes in the canal shape can be observed sooner. However it is impossible to formulate a true comparison of how the instruments would behave in root canals of real teeth. CE of nickel-titanium (NiTi) instruments is markedly different in resin vs. dentin. Kazemi, et al(7), stated in 1995 that acrylic was useful in measuring CE but does not cause the instrument to wear as rapidly as dentin.

Schafer used the acrylic blocks since his purpose was to determine CE, not instrument wear.

In the Schafer 2001 study, two degrees of curvature were tested, $28^{\circ}$ and $35^{\circ}$. Either a Hero 642 NTR file or a stainless-steel hand K-Flexofile was used to enlarge only one canal each. Glycerin was used as a lubricant. Once the canals were enlarged, the resin blocks 
were measured by someone unaware of the method of preparation. The Hero 642 were run at $400 \mathrm{rpm}$ and instrumented in a crown-down fashion with decreasing file tapers ( $6 \%$ to $4 \%$ to $2 \%$ size $20,4 \%$ to $2 \%$ with size $25,2 \%$ with size $30,2 \%$ with size 35 ) to the end of the canal. Reaming with the K-Flexofile was accomplished by working the canal up from a size \#15 to a \#35 ISO, without pre-bending. Assessment of canal shape was made with the Image 1.41 computer program. Pre-and post instrumentation canal shapes were compared. This allowed determination and measurement of canal transportation at different points, inner and outer along the canal. The results showed the Hero 642 NTR files to have quicker preparation time, better maintenance of working length in the $28^{\circ}$ canals, and have better centered enlargement than the K-files. The disadvantages are the added expense of the NTR files and the higher incidence at which they tend to separate under torsional or flexural stresses(21).

The $\mathrm{CE}$ of endodontic files has been of practical interest to the clinician. Prior to the advent of NTR instruments, stainless steel hand files were used for most of the shaping procedures. These early manual techniques were labor-intensive and time consuming.

Many materials and methods have been used over the years to test the CE of endodontic files. In 1980, moist bovine bone was used by Webber, et al (1) and Felt, et al (2), as a material of sufficient hardness to test CE. In Webber's study, the bone was taken from the femur of a cow and cut into $50 \mathrm{~mm}$ long pieces, machined to a smooth surface, wrapped in gauze, soaked in 
Ringer's solution and stored at $-20^{\circ} \mathrm{C}$. The bone was thawed prior to testing and always used in a moist condition. In this case, $\mathrm{CE}$ was measured as a function of weight loss from the instrumented bone.

Stenman and Spangberg (3), lamented the difficulties in developing a method to measure CE, such as controlling the load in the file and selection of material to be cut. They sought to identify the source of measuring errors and to suggest a reliable method for measuring CE. Acrylic blocks (polymethyl methacrylate, aka Plexiglas) were selected as the material to be cut because of the available strict control of thickness and hardness. Hedstrom files were tested in a filing motion of 60 strokes per minute, across a $7 \mathrm{~mm}$ range of motion with a constant load controlled at $100 \mathrm{~g}$. 300 filing strokes were used for each cycle on each side of the file. In this case, it was possible to test only one file at a time because the method for measurement involved the size of the cut area, not the weight of material removed (assessment of weight removed is more sensitive due to the small amount of material removed by one file). The machined grooves were traced on a transparent drawing film and the area calculated using a digitized film. The possible wear/ variation in $\mathrm{CE}$ of the instruments was tested with three cycles of 500 push-pull strokes each.

Haikel (11) contradicted this method based on the idea that Stenman was calculating CE based on a two-dimensional measurement, which would not be representative of the threedimensional reality of clinical conditions. Despite this criticism, Stenman's methods were 
utilized again in 2005 by Dearing and Kazemi, et al (26) with the addition of measuring CE in both dentin and Plexiglas.

Methods to measure the $\mathrm{CE}$ of these files were devised and refined for various materials to accept the instrumentation process. Testing the CE should involve a material of standardized, consistent hardness similar to dentin(6,11). Bovine bone was found to vary in hardness, as was human dentin. Acrylic blocks were found to consistently reproduce the hardness of dentin and thus affect the $\mathrm{CE}$ of files in a similar fashion(26). The method for determining the actual CE has also evolved from measuring the weight loss of material cut from the sample $(1,15)$, to tracing the cut outline in acrylic $(3,26)$, to measuring the maximum penetration of the file into the acrylic block $(6,14,22,30)$.

By 1995, Tepel, Schafer and Hoppe(6) had refined a computer-driven testing device to standardize conditions of instrumentation, using resin specimens with known abrasion characteristics. This device would continuously record on an x-t-recorder (as a function of time) the penetration depth of the root canal instrument into the lumen during each working cycle. Rotation angle, direction and speed were controlled. The x-t-recorder transcribed three phases of instrumentation. In the first phase, passive penetration, the resin block oscillates in a downward direction over the upward-directed file until contact with the lumen walls is made. The active penetration follows where the file proceeds into the lumen by cutting in a rotary motion. The 
end of the experiment occurs when the file has ceased to advance. The resin block used was of $5 \%$ weight quartz powder to simulate the hardness of dentin, with the lumen diameter of 0.30 mm used for \#25 instruments and $0.40 \mathrm{~mm}$ used for \#35 instruments. Instrumentation was done without irrigation as the authors found it to have an adverse affect on material removal when instrumenting resin. The downward-facing canal helped prevent the packing of chips in the apical part of the canal.

Hand files used in a rotary motion were more efficient than if used in a filing motion(6). Even more efficient are the NTR files(18). Add to this fact their ability to enlarge canals quickly, safely and to negotiate canal curvatures(30), the NTR files have become the standard-bearers in CE.

In 1996, Haikel and Serfaty, et al (11), introduced a new concept in measuring CE. They noted an absence of an accepted standard method to measure CE. Most studies had high standard deviations in their data which indicates the presence of many variables in the testing methods, not the least of which are applied loads to the cutting instrument. The test specimen must have comparable hardness to dentin but can be of more uniform hardness across all of the samples used. The new concepts in their testing method involved three parts. The first part combined linear and rotary motion by advancing the file with a quarter clockwise turn and then pulling it along its full working length. The second concept positions two test specimens of 
bovine bone to follow the taper of the instrument so that the force is evenly distributed along its full working length. Thirdly, the cut is made on brand new Plexiglas surfaces of uniform hardness similar to that of dentin. Each instrument was tested for four series of 25 quarter turns and withdrawals, and each withdrawal was made on a new Plexiglas surface. Water irrigation was utilized to ensure removal of debris during testing. $\mathrm{CE}$ was determined from the printout calculating the energy used to make each cut. CE loss was calculated from the first to the fourth usage.

Felt's study of hand instruments (2) in 1982 found significant differences where reamers cut more efficiently than files within a particular brand. Flute design was also significant. Too many flutes per millimeter meant that the file would more easily become clogged with dentin chip debris. Fewer flutes means better chip debridement. If the number of flutes is constant, then cross-section of the instrument becomes more significant. In this study, instruments with a square cross-section cut better than those with a triangular cross-section. This was contradicted by a later (1999) study by Schafer (14) that found cross-sectional configuration to be an important element in the determination of CE. The optimal combination of design elements was deemed to be a rhombus-shaped cross-section with 24 flutes. Either less (12 flutes) or more (36 flutes) with the same cross-section resulted in decreased CE. A later Schafer study (30) in 2008 
found "cross sectional design to be a more decisive parameter concerning the sharpness of rotary NiTi instruments than a surface treatment.”

CE of endodontic files has been studied to try to isolate preferred characteristics. Tepel, Schafer and Hoppe (6), in 1995, studied 24 different types of hand instruments (12 instruments, each type tested as a \#25 and \#35) with their computer-driven testing device, measuring maximum penetration into resin specimen. Stainless steel reamers and especially K-files cut more efficiently than Nitinol K-files. Flexible stainless steel instruments cut better than stainless steel reamers and K-files, and especially better that Nitinol K-files.

Several design features have been studied regarding their affect on CE. Reamers cut better than files due to their improved chip space(2). Whereas CE is not affected by the number of flutes, it is affected by cross-sectional design more than any other factor(14). Lubrication with irrigant while instrumenting improves $\mathrm{CE}(4)$.

Effect of irrigation/lubrication in testing CE has been dependent on the method used. The Schafer studies did not use any irrigation, as the system was set up to allow the machined dentin chips to fall away $(6,8,14,22,30)$. A study in 1990 by Yguel-Henry (4) found the CE to be improved by $200 \%$ for K-files with irrigation of an aqueous solution (2.5\% sodium hypochlorite or distilled water in the experiment had the same effect). 
Surface hardness of the file correlates with CE. The harder the surface, the better the $\mathrm{CE}(19)$. NTR files that were either Boron-(9) or ion-implanted(19) showed improved CE due to increased hardness. Physical Vapor Deposition (PVD) of titanium nitride improves hardness and increases CE by $26 \%$ without adding bulk. This is possible by increasing the surface hardness of the instrument. TiN gives the instrument a gold color. This sets it apart from the other coating materials in that as the instrument is used, the gold color dims, indicating wear of the cutting edges. Therefore PVD-coating could decrease instrumentation time and possibly lessen the risk of instrument separation (22).

The harder the surface, the more wear-resistant the cutting edges are and thus the longer the life of the instrument. NiTi files are difficult to manufacture because of the resilience of the alloy, the manufacturing process involves machining the NiTi wire rather than twisting it. The cutting edges can have structural defects, which will detrimentally affect the cutting ability. Lee, et al, in 1996 studied implantation of boron ions into the surface of a NiTi alloy and found the surface to have an increased hardness value, from $3.2 \pm 0.2 \mathrm{GPa}$ to $7.6 \pm 0.2 \mathrm{GPa}$. This was accomplished without affecting the flexibility of the instrument, adding cracks or peelings (9). Surface implantation with nitrogen ions onto the NTR ProFiles by Rapisarda, et al, showed that while the surface morphology was unchanged, the increased hardness allowed a longer shaping time within the canal without the wear seen in a similar but untreated instrument. The 
implication here is that the instrument could be used "to shape more pulp canals before being discarded." (19)

Electropolishing had no effect on CE. It is a process that manufactures claim decrease surface imperfections, thus increasing CE, but has been found to have no effect on the CE. It did not prevent the formation of microfractures and the process tended to round the instrument's cutting edges(29).

Composition of the metal has a significant effect on CE. Stainless steel, which is harder and less flexible, cuts better than nickel-titanium(10).

CE has been shown to decrease due to plastic deformation, surface damage or wear of the cutting edge. The sharper the cutting edge of the file, the quicker it wears and decreases its CE. $(5,7)$. Yguel-Henry concluded in 1994 that the sharper H-files are "more sensitive to CE modifications than (the less sharp) K-files." And in both instances CE decreased (H-files and Kfiles) due to cutting edge wear and bulk plastic deformation (5). When instrumenting human dentin, the $\mathrm{CE}$ of a hand file can rapidly deteriorate(7).

A study of the defects (evidence of microcracks and pitting of the surface) in NTR files after use noted the torsional fracture (55.7\%) and flexural fatigue (44.3\%) incidences (16). The authors (Sattapan, et al) suggested that instrument failure was related more to how the instrument 
was used (degree of curvature, tight canals and their resulting stresses) rather than how many times or how long it was used.

In 2002, Svec noted that 'Researchers and clinicians have not been able to agree on how many times a file can be used before being discarded," unless it has become fractured or distorted. The NTR Profile (.04 taper) was examined after 5 uses at $150 \mathrm{rpm}$ in an extracted tooth. A high torque load setting of $8 \mathrm{~N}$ was used. All instruments showed signs of wear after one use.

The notion that with usage and subsequent wear, pitting and microcracks develop within the 3-4 mm of the tip of the NTR ProTaper S1 file was discussed by Peng, et al (25). Debris accumulates there, leading to a sudden instrument separation. Therefore, instruments should be discarded after a certain number of uses. However, so far the number of uses has not been agreed upon (25).

The effects of cleaning, disinfection and sterilization procedures on the CE of hand files have been found to be only one group amongst many variables, too difficult to separate out as a single causative factor of decreased CE(12). However, Rapisarda, et al (1999) tested ProFiles' (an NTR file) CE with successive sterilization cycles and found a 20\% reduction in CE associated with 7 cycles. A 50\% reduction in CE was noted after 14 cycles. Therefore, sterilization cycles were found to have a direct correlation with CE. The more times an NTR file was sterilized (used), 
the poorer its $\mathrm{CE}$ would be and the longer time it would take to remove the same amount of material(15).

Contradictory to this was the Viana, et al study published in 2006(27). They found insignificant changes to the mechanical properties (not the $\mathrm{CE}$, but tensile strength and surface hardness) of NiTi endodontic instruments after 5 cycles of common sterilization procedures. This was less than the 7-14 cycles endured by the files in the Rapisarda study (15) but also might explain the discrepancy in the results. The 5 cycles might be more clinically relevant in testing practical CE loss. One has to believe that most clinicians are not going to be using NTR instruments beyond 5 uses/sterilization cycles.

With NTR files, the number of sterilization cycles affects the CE by altering the file's outer surface(15). Titanium oxide was deposited on the surface of sterilized instruments. The more they were sterilized, the more the amount of the deposits. These deposits were shown to decrease CE. But again, this is the study that subjected the files to 14 cycles of sterilization.

Sodium hypochlorite does not affect NiTi unless it is soaked overnight $(13,23)$. When instruments were cleaned by soaking in $\mathrm{NaOCl}$ for a short period (10 minutes), no effects were noticed affecting fracture susceptibility or corrosion(23). For practical clinical purposes, it seems reasonable to limit cleaning of files to a brief period of time when using $\mathrm{NaOCl}$. 


\section{Chapter 3: Materials \& Methods}

\section{Sample Description / Pilot Study Description}

Three brands of NTR endodontic files were tested for cutting efficiency when new and throughout five cycles of cutting into endodontic training blocks and heat sterilization. Nine samples of each brand were tested, with the tenth of each being used as the negative control. The three brands of instruments are the Brasseler Endosequence rotary file, the Sybron Endodontics K3 rotary file and the Tulsa-Dentsply ProFiles. All files were of size 0.06 taper and $0.35 \mathrm{~mm}$ in width at Do (ISO size \#35). A new endodontic training block made of acrylic resin with a similar hardness to human dentin (and presumably to cause wear similar to dentin) and with a simulated root canal lumen of diameter $0.20 \mathrm{~mm}$ at its orifice was used for each trial in which a $\mathrm{CE}$ measurement was to be recorded. $\mathrm{CE}$ was determined by measuring maximum penetration depth(D-Length) of the rotating file (set at $250 \mathrm{rpm}$ with constant force of $2.0 \mathrm{~N}$ ) into the lumen and by measuring the mass of acrylic removed during this process. This change in mass of the acrylic block (D-Mass) was measured by weighing the block before and after the CE penetration measurement. Clinical wear of the file was simulated by cleaning and shaping two canals in human teeth. For each file, this was repeated for five cycles, to simulate the cleaning and shaping of canals over five separate clinical usages. The initial trial occurred prior to the first 
clinical simulation, in order to measure the files' original CE. Therefore, there were six measurements (trials) with five clinical simulations of instrumenting human teeth between them.

\section{Experimental Protocol:}

1. Start up computer (Power up computer and monitor, turn on Instron machine. Double click on the Merlin icon. Select Series IX bar to start the Instron software program. Allow about 15 minutes to warm up.) Set Instron machine to limits of instrumentation (Upper unit to 57.7 $\mathrm{mm}$, lower unit to $55.7 \mathrm{~mm}$ ).

2. Set auto reverse to stop handpiece at $2.0 \mathrm{~N}$ of force upon penetration of the acrylic block.

The handpiece is to be run with constant pressure/rate of advancement and is turned on with a foot switch.

3. A new acrylic endodontic training block is weighed in the Mettler Balance and then, with its lumen facing downward, is secured into the machine's upper, movable vise.

4. The handpiece is secured in the lower, unmovable vise, with the NiTi rotary file to be tested pointing upward toward the acrylic block's lumen. A fixed acrylic device has been fabricated to hold the handpiece in position.

5. The cross-head of the Instron is lowered until the inferior border of the block is at the level of the file tip. 
6. The lower member's vise can be translated in an $\mathrm{x}$ or $\mathrm{y}$ plane to allow alignment for entry into the block's lumen.

7. The depth gauge on the software is manually reset to $0.0 \mathrm{~mm}$ with the Instron's "Reset GL" button.

8. The Balance Load is reset to $0.0 \mathrm{~N}$.

9. The handpiece is turned on $(250 \mathrm{rpm}$, Auto reverse at $2.0 \mathrm{~N})$

10. The auto reverse mechanism will stop the file's rotation once $2.0 \mathrm{~N}$ of torque is met within the limen. The penetration depth (cutting efficiency) reading will then be recorded.

11. The acrylic block is to be moved downward with the "Fine Positioning" dial at a constant rate until the rotating file binds. The downward movement is maintained with a force of not more than $200 \mathrm{~g}$ on the acrylic block. When $2.0 \mathrm{~N}$ of resistance is met, the handpiece automatically reverses without affecting the penetration depth (the block cannot raise away from the file without the operator manually dialing the cross-head upward).

12. Once the handpiece has shut down, the penetration depth is recorded.

13. The cross-head is raised, the acrylic block is removed, instrumented material is purged with an air stream from the lumen, and the block is reweighed. The file is removed, cleaned and prepared for sterilization.

14. Once the file's penetration depth and acrylic block mass have been recorded, the successive trials will include instrumentation of two canals of natural teeth for each file to simulate clinical use wear. The manufacturer's recommended operating speed was used for each file 
(Brasseler Endosequence, 600 rpm; Sybron K3, 350 rpm; Tulsa ProFile, 300 rpm). Sodium hypochlorite (5\%) irrigation and lubrication was used. Each canal had a glide path created in the canal with standard stainless steel K-files (\#10,15 20). The files were then cleaned of visible debris with an alcohol sponge and heat sterilized in the WVU School of Dentistry central processing unit. Then the above-described experiment was repeated in order to measure the $\mathrm{CE}$ ( penetration depth of each file along with before and after mass measurements of the blocks). The instrumentation cycles of teeth, then blocks, were done five times for each file. For each file type (3), there was a control where natural teeth were neither instrumented nor sterilized between the trials with the blocks.

15. Once finished, software program was exited by clicking on "Exit to Windows." Computer, monitor and Instron machine were then shut down.

\section{Method of data collection}

Maximum file penetration was measured in millimeters as movement of the cross-head. This will represent the file's CE (D-Length).

Change of mass (D-Mass) of the acrylic block is also recorded in milligrams to measure amount of material removed during the instrumentation as a second indication of CE. 


\section{Data analysis}

The mean values of CE for a specific cycle (first or second or third, etc. cutting trial for the nine files of each of the three brands) were calculated. The tenth file of each brand was used as a negative control. Mean change in $\mathrm{CE}$ from the first to the sixth cut for each brand of file was determined. Data was evaluated for significant differences using ANOVA and Tukey HSD test. JMP software was used for the statistical analysis. 


\section{Chapter 4: Results}

CE of NTR files was measured with two different methods. The first method involved measuring the depth of penetration that the file entered into an acrylic endodontic training block. The second entailed measuring the mass of the material removed from the block by the file. The objective was to determine the change in CE over the course of five clinical usage simulations. The CE of each file was measured (Trial \#1) initially. There were five clinical usage simulations, each followed by a CE measurement for a total of six CE measurements. Two canals of human teeth were then instrumented with each file, the file cleaned and heat sterilized, and then run through the second measurement (Trial \#2) of penetration and change of mass of the acrylic block. The control files (which were measured in the same manner but without any tooth preparation) showed no statistical differences in either penetration or mass change of the blocks. 


\section{Penetration by File}

$\begin{array}{lrrrr}\text { Level } & & & \text { Mean }(\mathrm{mm}) & \text { Std Error } \\ \text { B } & \text { A } & & 12.11 & 0.33 \\ \text { K3 } & & \text { B } & 10.87 & 0.33 \\ \text { PF } & & \text { B } & 10.68 & 0.33\end{array}$

Means with the same letter are not statistically different (Tukey HSD Test)

Table 1: Penetration(mm) by File Brand

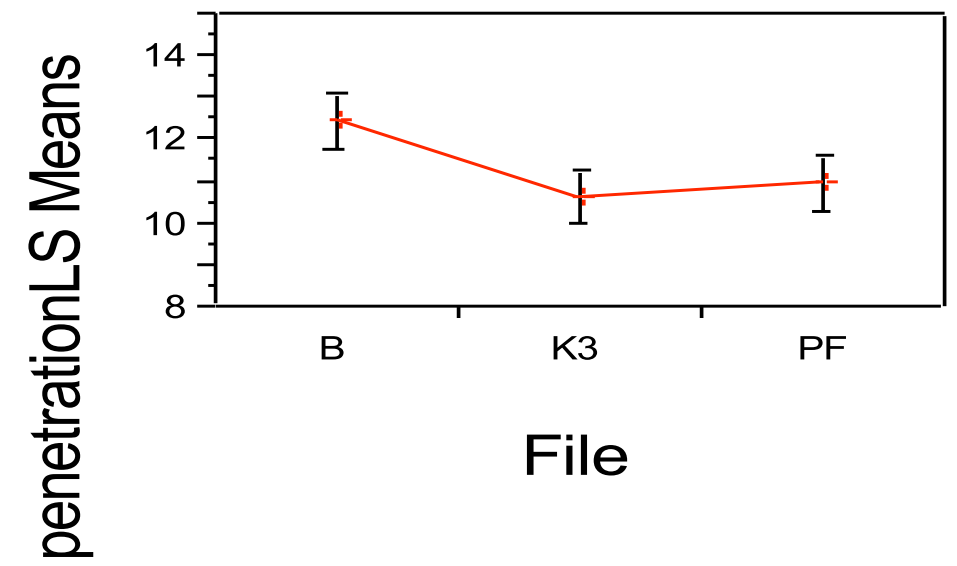

\section{Graph 1: Mean Penetration(mm) by File Brand}

ANOVA test showed a significant difference between files $(p=0.0003)$. Using a TukeyKramer Analysis, the Brasseler EndoSequence (B) file was found to penetrate the blocks 
significantly deeper than either the Dentsply ProFile (PF) or the Sybron K3 (K3) (Mean penetration depths of $\mathrm{B}=12.11 \mathrm{~mm}, \mathrm{~K} 3=10.87 \mathrm{~mm}, \mathrm{PF}=10.68 \mathrm{~mm}$ ). The $\mathrm{PF}$ and the $\mathrm{K} 3$ were not found to be statistically different (Table 1, Graph 1).

$\begin{array}{lrr}\text { Trial } & \text { Mean }(\mathrm{mm}) & \text { Std Error } \\ 1 \text { (Initial) } & 11.37 & 0.19 \\ 2 & 11.51 & 0.19 \\ 3 & 11.25 & 0.19 \\ 4 & 11.24 & 0.19 \\ 5 & 10.97 & 0.2 \\ 6 & 10.92 & 0.21\end{array}$

Table 2: Penetration(mm) by Trial

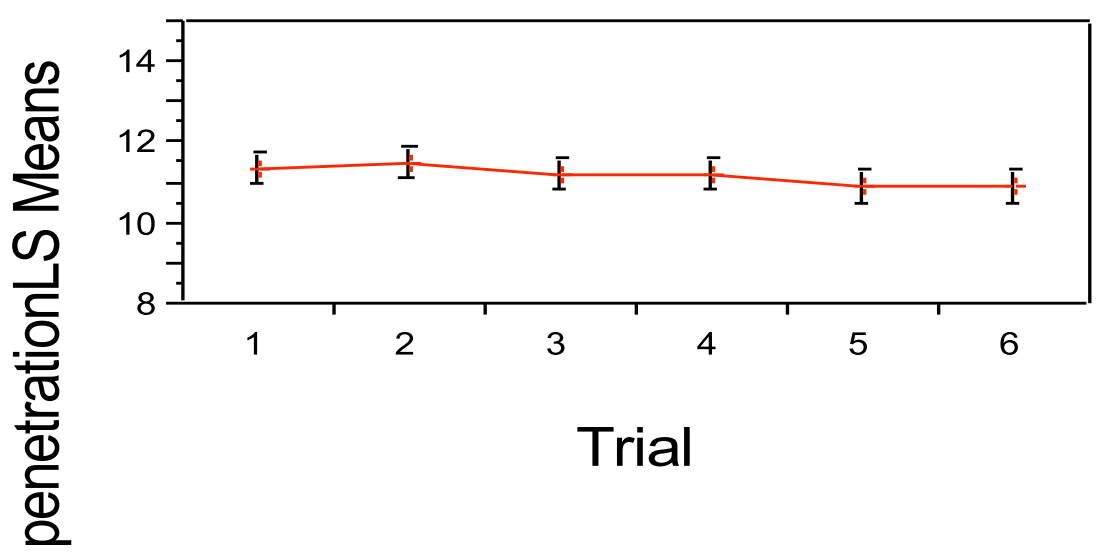

Graph 2: Mean Penetration(mm) by Trial. Error bar indicates Standard Error. 
No differences in CE were found over the course of the six trials (ANOVA, $p=0.2550$ ). In other words, the overall average of CE's of all three file systems did not change as they were subjected to the five clinical simulations (Table 2, Graph 2).

\section{Change of Mass Results by File}

$\begin{array}{lrrr}\text { Level } & & \text { Mean(mg) } & \text { Std Error } \\ \text { B } & \text { A } & 2.1 & 0.2 \\ \text { K3 } & \text { B } & 0.5 & 0.2 \\ \text { PF } & \text { B } & 0.7 & 0.2\end{array}$

Means with the same letter are not statistically different (Tukey HSD Test)

Table 3: Means for D-Mass(mg) by File Brand

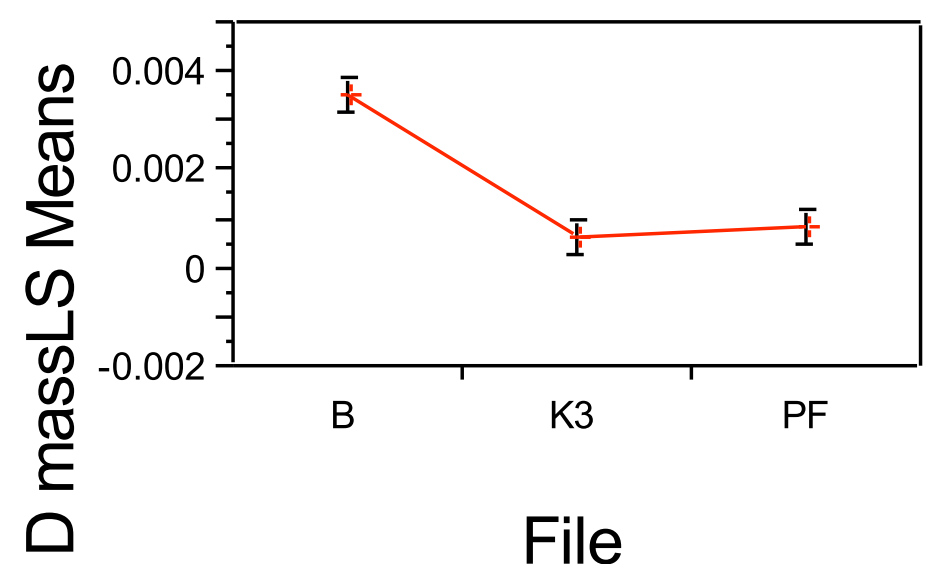

Graph 3: Means for D-Mass(g) by File Brand Error bar indicates Standard Error 
ANOVA test showed a significant difference between files for the change in mass (D-Mass) ( $p$ $<0.0001)$. The Tukey-Kramer test found the B files $(2.1 \mathrm{mg})$ removed more of the acrylic block than either the PF $(0.7 \mathrm{mg})$ or the K3 $(0.5 \mathrm{mg})$ files. The PF and the K3 files were not statistically different (Table 3, Graph 3).

\section{Change of Mass Results by Trial}

$\begin{array}{lrrr}\text { Trial } & & \text { Mean }(\mathrm{mg}) & \text { Std Error } \\ 1 & \text { A } & 1.7 & 0.1 \\ 2 & \text { A B } & 0.9 & 0.1 \\ 3 & \text { B } & 0.8 & 0.1 \\ 4 & \text { A B } & 1.1 & 0.1 \\ 5 & \text { A B } & 1.3 & 0.1 \\ 6 & \text { B } & 0.8 & 0.1\end{array}$

Table 4: Means for D-Mass(mg) Arranged by Trial

Means with the same letter are not statistically different (Tukey HSD Test) 


$\begin{array}{lrrr}\text { Trial } & & & \text { Mean(mg) } \\ 1 & \text { A } & 1.7 \\ 5 & \text { A } & \text { B } & 1.3 \\ 4 & \text { A } & \text { B } & 1.1 \\ 2 & \text { A } & \text { B } & 0.9 \\ 6 & & \text { B } & 0.8 \\ 3 & & \text { B } & 0.8\end{array}$

Table 5: D-Mass(mg) Arranged by Means

Means with the same letter are not statistically different (Tukey HSD Test)

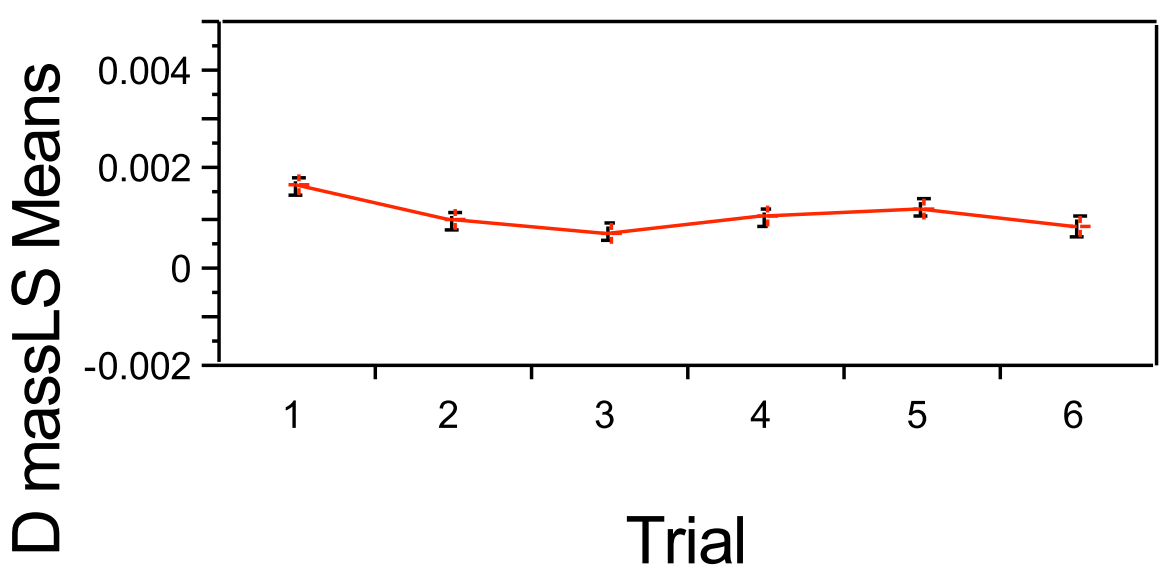

Graph 4: Least Square Means for D-Mass. Error bar indicates Standard Error. 
Analysis of D-Mass by trial with the Tukey HSD Test showed a statistically significant

difference between trial 1 versus trials 6 and 3. Without a progressive reduction in CE from trials 1 through 6, this result is not considered to be clinically relevant(Tables 4,5; Graph 4).

\section{Change of Mass by Trial and File}

\begin{tabular}{rrrr} 
Trial & B & PF & K3 \\
2 & 1.7 & 0.9 & 0.4 \\
3 & 1.6 & 0.3 & 0.4 \\
4 & 2.2 & 0.6 & 0.4 \\
5 & 1.9 & 0.9 & 0.8 \\
6 & 1.5 & 0.6 & 0.4 \\
\hline Mean & 1.8 & 0.7 & 0.5
\end{tabular}

Table 6: D-Mass(mg) Means by File, Trials \#2 - 6 


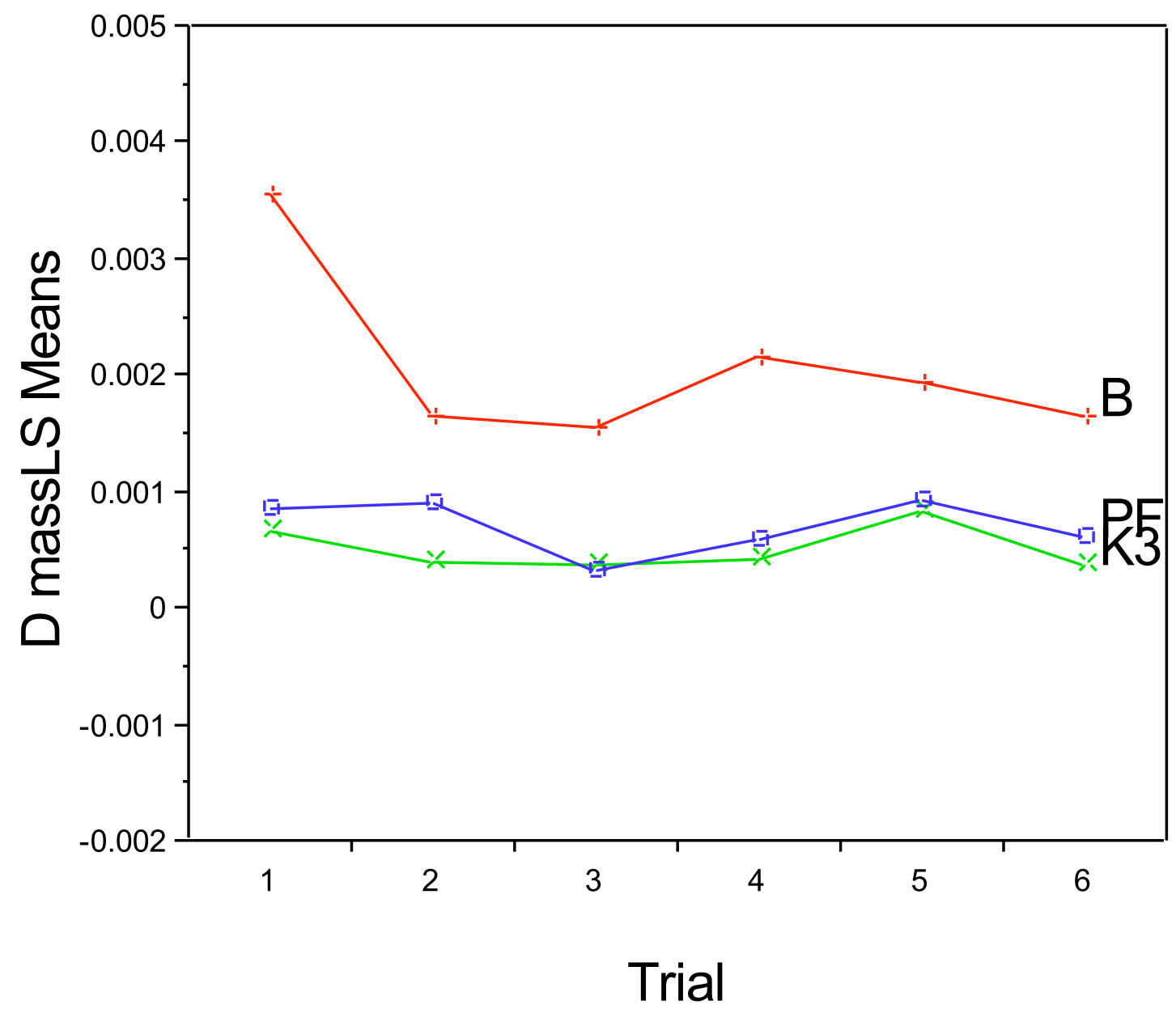

Graph 5: D-Mass(g) Least Square Means by Trial and File Brand

The B files' CE in the first trial was higher than the other B trials and all of the PF and K3 trials. Further analysis in D-Mass of Trials 2 through 6 were studied, thus excluding the outlying B Trial 1. The graphic representation of the D-Mass CE's of the three file brands' trials 2 through 6 reveals that after trial 1, the CE's changed little. An arithmetic mean was determined for trials 2 through 6 for each file system and compared. Once again, the D-Mass CE for the B 
file $(1.8 \mathrm{mg})$ is significantly higher than with either the PF $(0.7 \mathrm{mg})$ or the $\mathrm{K} 3(0.5 \mathrm{mg})$ systems tested.

File separation occurred twice with the Brasseler files and once with the ProFiles throughout the course of this experiment. One ProFile separated while measuring penetration into an acrylic block during its fifth measurement cycle. Two Brasseler files separated while instrumenting human teeth during their fifth and final clinical simulation. No K3 files separated. 


\section{Chapter 5: Discussion}

The CE of NTR files is dependent upon several aspects of file design. The three systems were chosen for this study because of their distinct differences in cross-sectional design. The Brasseler EndoSequence files, with its negative rake angle, non-landed flutes and plentiful chip space was expected to have the higher CE. This was found to be true. The taper of the Brasseler was also varied. The manufacturer referred to this as the Alternating Contact Point Design (ACP). This centers the file in the canal without radial lands, prevents self-threading and enhances debris removal. The lack of the radial lands maximizes flexibility while minimizing torque. The Brasseler had the steepest drop in CE between trials (Trials 1 and 2). This supported the literature's claim that the sharpest files lose their CE the quickest $(5,7)$. However, in spite of the Brasseler's CE drop between trials 1 and 2, its CE from trials 2 through 6 stabilized and maintained a consistent level of CE that was still higher than either of the other two systems. Two of the ten Brasseler files separated in the final trial, while instrumenting natural teeth. 
Electropolished Surface

- Eliminates surface imperfections

that weaken other files

- Increases file sharpness

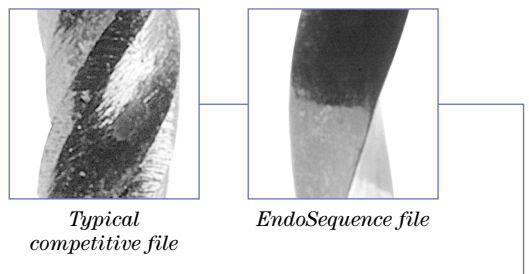

Precision Tip

- Non-active at the tip, fully active precisely at $1 \mathrm{~mm}$

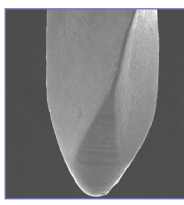

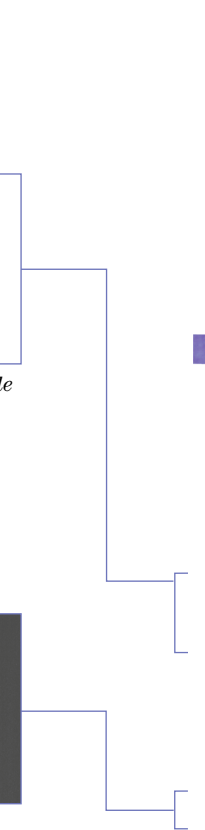
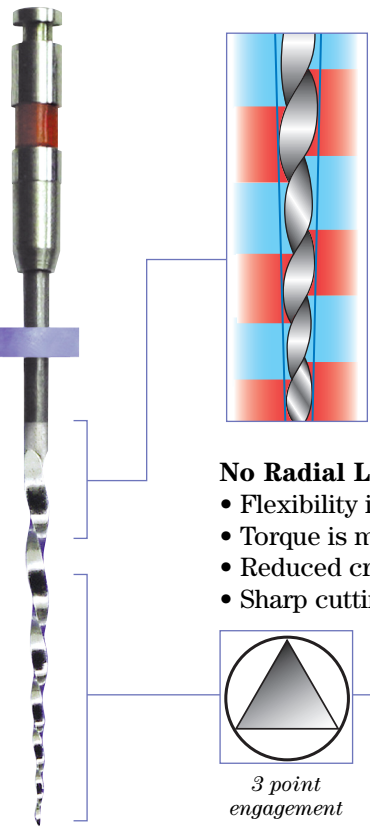

Patented ACP

(Alternating Contact Point $^{\mathrm{TM}}$ )

Design

- Centers file within canal without radial lands

- Prevents self-threading "screw in"

to canal

- Enhances debris removal

- Maximizes cutting efficiency

No Radial Lands

- Flexibility is maximized

- Torque is minimized

- Reduced cross section thickness

- Sharp cutting edge

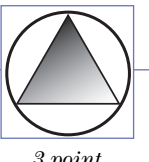

3 point

engagement

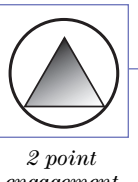

engagement

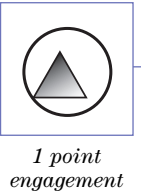

No

Figure 3: Brasseler EndoSequence 
The K3 system is designed with a positive rake angle, the cutting edges are landed and the chip space, in comparison with the Brasseler, seems to be reduced. The K3's CE was found to be less than the Brasseler's and statistically the same as the ProFile's.

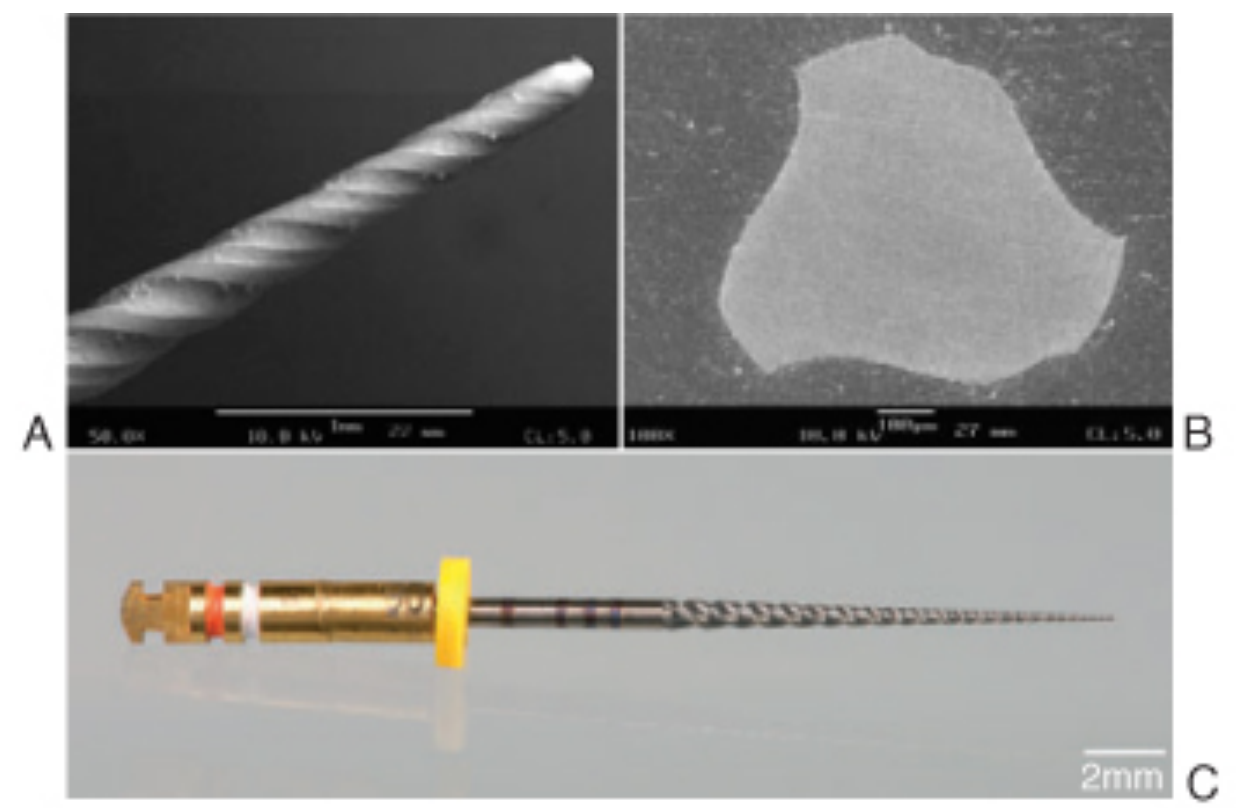

\begin{tabular}{|l|l|l|l|l|}
\hline $\begin{array}{l}\text { No. of } \\
\text { instruments/ } \\
\text { set }\end{array}$ & Tip sizes & $\begin{array}{l}\text { Size } \\
\text { increments }\end{array}$ & $\begin{array}{l}\text { r.p.m. } \\
\text { (recommended) }\end{array}$ & Lengths \\
\hline 27 & $\begin{array}{l}15-45 \text { with } \\
.02 \text { taper; } \\
15-60 \text { with } \\
.04 \text { and } \\
.06 \text { taper }\end{array}$ & 5 & $\begin{array}{l}300 \text { to } 350, \\
\text { minimal axial } \\
\text { force }\end{array}$ & $\begin{array}{l}21,25, \\
30 \mathrm{~mm}\end{array}$ \\
\hline
\end{tabular}

Copyright (c) 2006, Elsevier, Inc.

Figure 4: Sybron K3 NTR File 
The ProFiles system was selected for its negative rake angle. Its cutting edges are also landed. The CE findings for the ProFile was found to be statistically similar to the K3 and less efficient than the Brasseler.

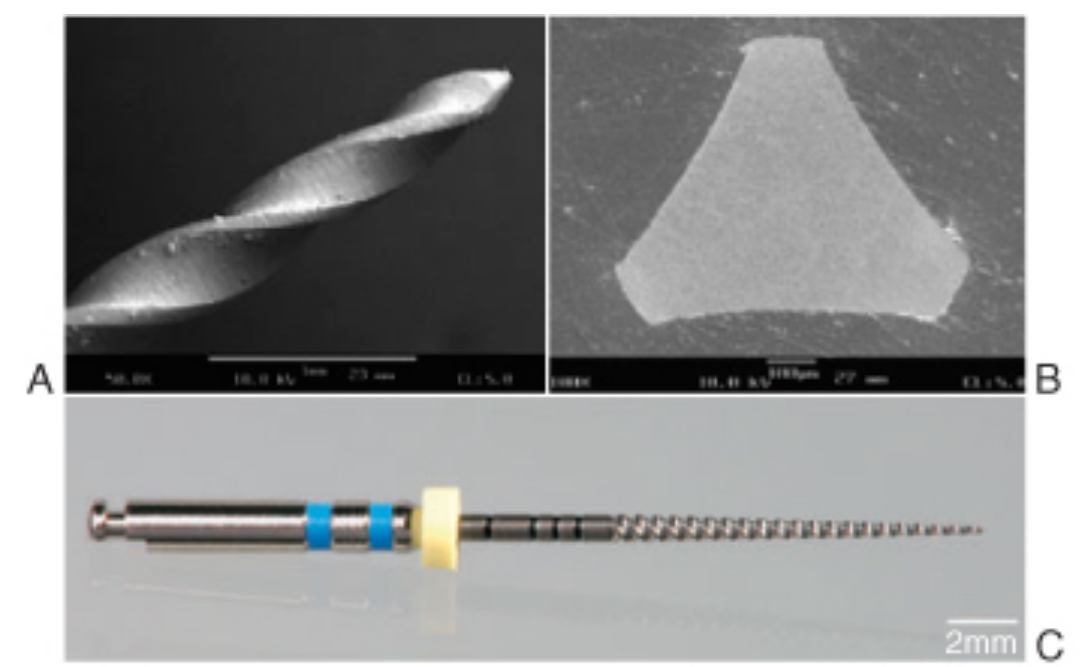

\begin{tabular}{|c|c|c|c|c|}
\hline $\begin{array}{l}\text { No. of } \\
\text { instruments/ } \\
\text { set }\end{array}$ & Tip sizes & $\begin{array}{l}\text { Size } \\
\text { increments }\end{array}$ & $\begin{array}{l}\text { r.p.m. } \\
\text { (recommended) }\end{array}$ & Lengths \\
\hline $\begin{array}{l}\text { Orifice } \\
\text { Shapers: } 6\end{array}$ & $20-80$ & $\begin{array}{l}10 ; \text { from } \\
60: 20\end{array}$ & $\begin{array}{l}150 \text { to } 350 \text {, } \\
\text { low apical force, } \\
\text { torque to }\end{array}$ & $\begin{array}{l}19 \mathrm{~mm} \\
21 \mathrm{~mm} .\end{array}$ \\
\hline ProFile $.06: 6$ & $15-40$ & 5 & $\begin{array}{l}\text { fracture and } \\
\text { working torque }\end{array}$ & $\begin{array}{l}25 \mathrm{~mm} \text {, } \\
\text { some }\end{array}$ \\
\hline ProFile .04: 9 & $15-90$ & $\begin{array}{l}\text { 5; from } \\
\# 45: 15 ; \\
\text { from \#60: } 30\end{array}$ & $\begin{array}{l}\text { dependent on } \\
\text { instrument size }\end{array}$ & 31 mm \\
\hline ProFile .02: 6 & $15-45$ & 5 & & \\
\hline $\begin{array}{l}\text { Profile } \\
\text { Series } 29\end{array}$ & $13-100$ & Varies, $29 \%$ & & $\begin{array}{l}21 \mathrm{~mm} \text {, } \\
25 \mathrm{~mm}\end{array}$ \\
\hline
\end{tabular}

Copyright (C) 2006, Elsevier, Inc.

\section{Figure 5: Dentsply - Tulsa ProFile}


The design differences of the three file brands had distinct differences in tactical characteristics when engaging either the acrylic or human dentin. The non-landed Brasseler files cut quickly, chattering once engaged in the canal and reached maximum torque more slowly and with more forewarning than the landed files. The Brasselers routinely caused the premonitious beep of increased torque load by the handpiece prior to binding and auto-reversal while the landed ProFiles and K3's had a sudden binding without the warning of a beep. The landed files entered the canals slower and smoother.

The K3 and the ProFile appeared to be very consistent as the six trials progressed. The CE data for those two file systems remained similar throughout the six trials as their CE did not decrease.

Whereas the differences in CE were observed between the systems, probably for the design differences stated above, the only large decrease in CE seen between trials was in the case of the Brasseler files, between trials 1 and 2. All other CE's measured for each of the file systems proved to remain the same. Clinically, this consistency indicates that the operator's overall efficiency will not be affected by the re-using of these NTR files. The main concern in the re-use of these files would therefore be the risk of file separation from metal fatigue. However, based on the high CE of the brand new Brasseler file, it would behoove the operator who enjoys such highly efficient cutting to use a new Brasseler EndoSequence file for each case.

During this experiment, file separation occurred twice with the Brasseler files and once with the ProFiles. Given the aggressive nature of the experimental design (file penetration at a 
constant rate at $2 \mathrm{~N}$ into an unforgiving acrylic block), the fact that only three file separations occurred over 180 trials speaks of the resilience of these NTR files. Both of the Brasseler separations occurred during the final trial, while instrumenting human teeth, in relatively tight canals. As suggested in the Sattapan study(16), instrument failure can be influenced more by the mode of use (degree of canal curvature, canal size, operator manipulations, etc) than by the number of usages. One ProFile separated while measuring penetration into an acrylic block. The file bound in the block as it penetrated deeper than $13 \mathrm{~mm}$ (a range of $9-11 \mathrm{~mm}$ was normal). It was speculated that the file could have been a bit dull, generating more heat as it burnished more than cut, and melted the acrylic. The file could not be removed from the block intact. No K3 files separated. No files separated before the 5th trial. One has to believe that no reasonable operator is going to use a NTR file more than five times. 


\section{Chapter 6: Conclusions}

The experimental results support the null hypothesis that there would not be a significant decrease in CE as the NTR files were used five times in simulated clinical conditions. The Brasseler NTR files cut more efficiently than the ProFile or the K3. Thus the main deterrent against multiple usages of these files remains the risk of file separation. 


\section{References}

1.Webber J, Moser JB, Heuer MA, A method to determine the cutting efficiency of root canal instruments in linear motion, JOE, November 1980; Volume 6, issue 11, 829-834

2.Felt, RA, Moser, JB, Heuer, MA, Flute design of endodontic instruments: its influence on cutting efficiency. JOE, June 1982, 8(6) 253-259.

3.Stenman E, Spangberg LSW, Machining efficiency of endodontic files: a new methodology, JOE, April 1990; Volume 16 Issue 4, 151-157.

4.Yguel-Henry, S, Vannesson, H, von Stebut, J, High precision, simulated cutting efficiency measurement of endodontic root canal instruments: Influence of file configuration and lubrication, JOE, September, 1990, 16(9), 418-422.

5.Yguel-Henry S, von Stebut J, Cutting Efficiency Loss of Root Canal Instruments due to Bulk Plastic Deformation, Surface Damage, and Wear, JOE, August 1994; Volume 20, No. 8, 367-372.

6.Tepel J, Schafer E, Hoppe W, Properties of endodontic hand instruments used in rotary motion. Part 1. Cutting efficiency, JOE, August 1995; Volume 21, Issue 8, 4128-421.

7.Kazemi RB, Stenman E, Spangberg LSW, The Endodontic File is a Disposable Instrument, JOE, Sept. 1995; Volume 21, No. 9: 451-455.

8.Schafer E, Tepel J, Hoppe W, Properties of endodontic hand instruments used in rotary motion. Part 2. Instrumentation of curved canals, JOE, October 1995; Volume 21, Issue 10, 493-497.

9.Lee, D., Park, B., Saxena, A., Serene, T., Enhanced surface hardness by boron implantation in nitinol alloy, JOE, October, 1996, 22(10), 543-546.

10.Schafer E, Tepel J, Cutting efficiency of Hedstrom, S and U files mad of various alloys in filing motion, International Endodontic Journal, September 1996; Volume 29, Issue 5, 302-308.

11.Haikel Y, Serfaty R, Lwin TT, Allemann C, Measurement of the cutting efficiency of endodontic instruments: a new concept, JOE, December 1996; 22(12), 651-656. 
12.Haikel Y, Serfaty R, Bleicher P, Thin-Thin CL, Allemann C, Effects of cleaning, disinfection, and sterilization procedures on the cutting efficiency of endodontic files, JOE, Dec. 1996; Volume 22, Issue 12: 657-661.

13.Haikel Y, Serfaty R, Wilson P. Speisser JM, Allemann C, Cutting efficiency of nickel-titanium endondontic instruments and the effect of sodium hypochlorite treatment. JOE, November 1998; Volume 24, Issue 11, 736-739.

14.Schafer, E., Relationship between design features of endodontic instruments and their properties. Part 1. Cutting efficiency. Joe, January, 1999; 25(1), 52-55.

15.Rapisarda E, Bonaccorso A, Effect of sterilization on the cutting efficiency of rotary nickeltitanium endodontic files, Oral Surgery, Oral Medicine, Oral Pathology, Oral Radiology, \& Endodontics, September 1999; 88(3) 343-347.

16.Sattapan, B, Nervo GJ, Palamara JEA, Messer HH, Defects in Rotary Nickel-Titanium Files After Clinical Use, JOE, March 2000, Volume 26, Issue 3, 161-165.

17.Schafer, E., Zapke, K., A comparative scanning electron microscopic investigation of the efficiency of manual and automated instrumentation of root canals. JOE, November, 2000; 26(11), 660-664.

18.Schafer, E., Shaping ability of Hero 642 rotary nickel-titanium instruments and stainless steel hand K-Flexofiles in simulated curved root canals. Oral Surgery, Oral Medicine, Oral Pathology, Oral Radiology \& Endodontics, August, 2001, 92(2), 215-220.

19.Rapisarda E, Bonaccorso A, Tripi TR, Condorelli GG, Torrisi L, Wear of Nickel-Titanium Endodontic Instruments Evaluated by Scanning Electron Microscopy: Effect of Ion Implantation, JOE, September 2001; Volume 27, Issue 9, 588-592.

20.Svec TA, Powers JM, The Deterioration of Rotary Nickel-Titanium Files under Controlled Conditions, JOE, February 2002; Volume 28, Issue 2, 105-107.

21.Weiger R, ElAyouti A, Lost C, Efficiency of Hand and Rotary Instruments in Shaping Oval Root Canals, JOE, August 2002; Volume 28, Issue 8, 580-583. 
22.Schafer E, Effect of sterilization on the cutting efficiency of PVD-coated nickel-titanium endodontic instruments, International Endodontic Journal, October 2002; 35(10), 867-872.

23.O'Hoy PYZ, Messer HH, Palamara JEA, The effect of cleaning procedures on fracture properties and corrosion of NiTi files, International Endodontic Journal, November 2003; 36(11), 724-732.

24.Peters, O., Current challenges and concepts in the preparation of root canal systems: A review. JOE, August, 2004, 30(8), 559-567.

25.Peng B, Shen Y, Cheung G, Xia T, Defects in ProTaper S1 instruments after clinical use: longitudinal examination, International Endodontic Journal, August 2005; 38(8), 550-557.

26.Dearing G, Kazemi R, Stevens R, A Comparison of the Machining Efficiency of Two Brands of Stainless Steel Endodontic Hand Files, JOE, December 2005; volume 31, Issue 12, 873-876.

27.Viana, ACD, Gonzales BM, Buono VTL, Bahia MGA, Influence of sterilization on mechanical properties and fatigue resistance of nickel-titanium rotary endodontic instruments, International Endodontic Journal, September 2006; Volume 39, Issue 9, 709-715.

28.Herold KS, Johnson BR, Wenckus CS, A Scanning Electron Microscopy Evaluation of Microfractures, Deformation and Separation in EndoSequence and Profile Nickel-Titanium Rotary Files Using an Extracted Molar Tooth Model, JOE, June 2007; Volume 33, Issue 6, $712-714$.

29.Bui TB, Mitchell J, Baumgartner, JC, Effect of Electropolishing ProFile Nickel-Titanium Rotary Instruments on Cyclic Fatigue Resistance, Torsional Resistance, and Cutting Efficiency, JOE, February 2008; Volume 34 Number 2, 190-193.42

30.Schafer E, Oitzinger M, Cutting Efficiency of Five Different Types of Rotary Nickel Titanium Instruments, JOE, February 2008; Volume 34, Number 2, 198-200.

31.Kinney J, Marshall S, Marshall G, The Mechanical Properties of Human Dentin: A Critical Review and Re-evaluation of the Dental Literature, Critical Reviews in Oral Biology \& Medicine, 14(1):13-29 (2003) 
32.Craig R, Ed. Restorative Dental Materials, Eighth Edition, C V Mosby Company, 1989. p.100.

33.Sattapan B, Palamara J, Messer H, Torque During Canal Instrumentation Using Rotary Nickel-Titanium Files, JOE, March 2000; Volume 26, Number 3, 156-160.

34. Cohen S, Hargreaves K, Pathways of the Pulp, Ninth Edition, Mosby Elsevier, 2006. p.305. 


\section{Curriculum Vitae}

\section{Employment:}

$1990-2007$

Private Practice, General Dentistry, Canonsburg, PA

$1987-1990$

Associate Dentist, Washington, PA

$1998-2003$

Visiting Faculty, L.D. Pankey Institute, Key Biscayne, FL

Education:

2007 - Present

Endodontics Residency, West Virginia University Morgantown, WV

1987

Graduated, University of Pittsburgh, School of Dental Medicine

1986

Graduated, Bachelors Degree in Chemistry

West Virginia University

1979

Graduated, Canon-McMillan H.S.

Canonsburg, PA

Interests:

Art (painting, drawing of wildlife, portraiture, figure), music (guitar), bicycling, karate, reading (mostly nonfiction, technical, some classic literature) and the truth. 